\title{
GIS Application for Estimating the Current Status of Municipal Solid Waste Management System: Case Study of Chandigarh City, India
}

\author{
A. Khajuria", T. Matsui and T. Machimura \\ Division of Sustainable Energy and Environmental Engineering, Graduate School of Engineering, Osaka \\ University, Yamadaoka 2-1, Suita, Osaka 565-0871, Japan \\ E-mail:anupam@ge.see.eng.osaka-u.ac.jp
}

Received: 20.10.2011, Accepted: 12.12.2011

\begin{abstract}
The population growth in many urban cities and its urban activities in developing countries have resulted in an increased generation rate of municipal solid waste(MSW), an important issue. In the process of municipal solid waste management (MSWM) system in which, collection activities contributed the most of total cost that is paid for MSW collection activities by city's citizen; and transport activities are required $60-70 \%$ of total cost that is the total expenditures spent on the transport, transfer, disposal and treatment of MSW by city authorities. Hence optimization of routing system, systematization of collection, transport and transfer activities is the important components for an effective MSWM system. This article describes the current problems and the improvement of the management activities in a city of Chandigarh. An integrated MSWM assessment model is proposed and used as a decision support tool for daily efficient operations such as collection/ transport path management, load balancing within vehicles, fuel consumption management by using GIS application. In addition, a simple optimal routing model is proposed to achieve the minimum cost/distance/time efficient collection and transport path for MSWM.
\end{abstract}

Key words: municipal solid waste management, route optimization, waste collection, transport and transfer optimization, GIS.

\section{Introduction}

Rapid growth of urban population in developing Asian countries in recent years has made MSWM an important issue. India is facing serious environmental problems in MSWM that is really threatened by a number of problems; some of which include inadequate management, lack of technology and human resources, a shortage of collection and transport vehicles, and insufficient funding.

In general, an effective MSWM system should include one or more of the following options: waste collection, transportation and transfer; intermediate treatment, reduce- reuse-recycle (3R) activities and disposal. The waste collection, transport and transfer methods depend on the specific site, waste generated, distribution road network, manpower, vehicles, treatment methods, etc. It is ensured that MSWM is environmentally safe and sustainable disposal (Khajuria et al., 2010).

Geographical Information Systems (GIS) is an information system for capturing, storing, analyzing, managing and presenting 


\section{A. Khajuria, T. Matsui and T. Machimura / Our Nature (2011) 9: 26-33}

data which are spatially referenced. It consists of a geo-referenced spatial database and it also includes all required parameters for MSWM. These parameters involve city maps, collection points, transfer stations, collection and transportation road network, as well as the location and capacity of disposal sites (Sharholy et al., 2007). ArcMap software has the capability to input and store the geographic (coordinate) and tabular (attribute) data, to find specific features based on location or attribute value regarding the interaction between multiple datasets, to visualize geographic features using a variety of symbols and to display the results in a variety of formats such as maps and graphs. In addition, it can be used to display, edit, create and analyze GIS data; browse, find and present geographic information of management system.

Recently, there has been an increase in research that uses GIS application as a tool for data collection, data analysis and result display. Ghose et al. (2006) found that GIS application used an optimal routing model that was proposed to determine the minimum cost/distance efficient collection paths for waste collection and transport. Wilson and Vincent (2008) used the Global Positioning System (GPS) to estimate the delay time of waste transfer stations. Sharholy et al. (2007), noted that GIS application has been used to analyze existing maps and data, was generated to give the efficient information concerning static and dynamic parameters of MSWM problems; and the emission control with route optimization in solid waste collection process used GIS application (Apaydin and Gonullu, 2008).

Optimization of the operational efficiency for collection, transport and transfer becomes an important component of an effective MSWM system. In this study, an assessment to estimate the operational efficiency of waste collection, transport and transfer system is conducted; and the MSWM model using GIS application as a decision support tool by municipal authorities for the efficient management in waste collection, transport and transfer system, load balancing within vehicles, managing fuel consumption, and generating work schedules for the workers and vehicles are proposed.

\section{Study area and current status}

Chandigarh is located near the foothills of the Shivalik range of the Himalayas in Northwest India. It covers an area of approximately $44 \mathrm{~m}^{2}$ or $114 \mathrm{~km}^{2}$ and shares its borders with the states of Haryana in the east and Punjab in the north, west and south (Fig. 1). Chandigarh city is an urban area directly under the state government and is regarded as a "Chandigarh Capital Region (CCR)", with a population of $1,064,711$ (2010), and geographic area of $13,256 \mathrm{~km}^{2}$.

Solid waste includes garbage, sewage sludge and other materials which are in solid state. Broad categories of solid waste may include: food waste such as vegetable, fruit or meat residues; rubbish such as waste papers, broken crockery, used cans, discarded house material, leather or furniture items; ashes such as wood, coal, and dung cakes; construction waste such as dirt, stones, concrete and bricks from demolished buildings; industrial wastes from factories; plant wastes from trees or pruned hedges; sewage from toilets and special wastes such as animal dung and dead animals (Krishna, 1996).

Chandigarh 'the city beautiful' is one of the cleanest cities of India. It produces around 350 TPD of solid waste, which is 0.4 


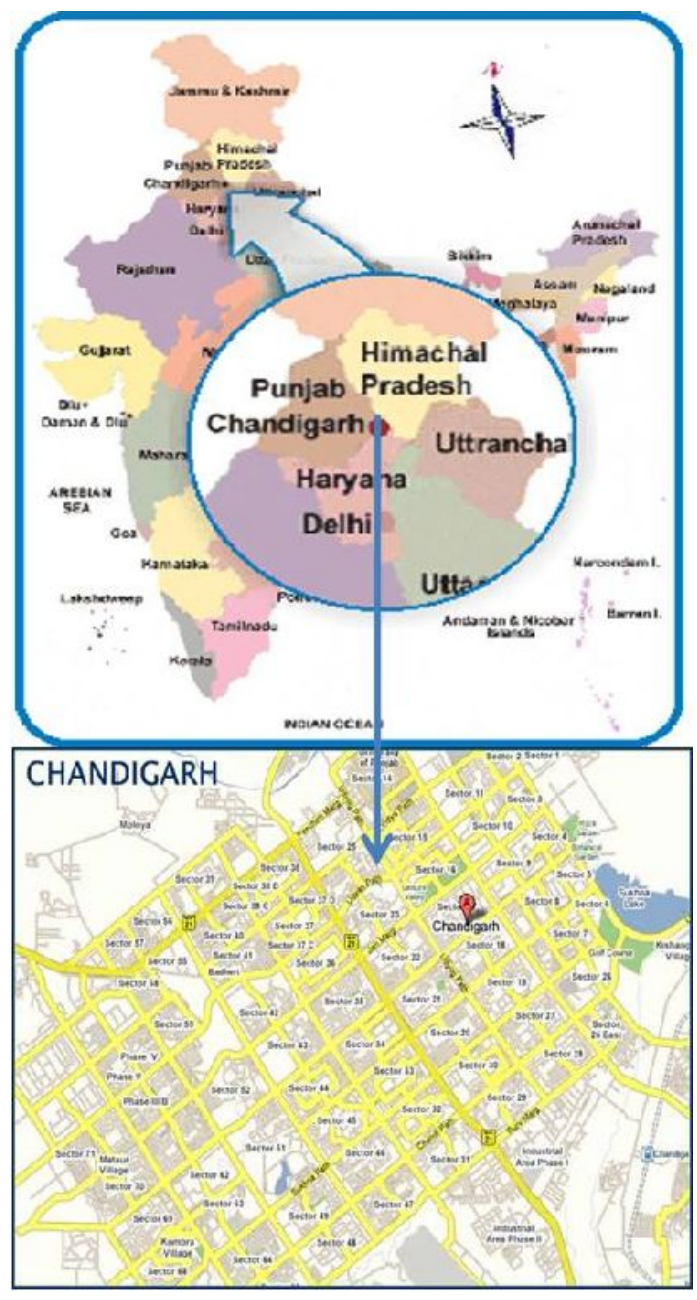

Figure 1. Map of research area (http://gauransh.com/sale.html).

$\mathrm{kg} / \mathrm{c} / \mathrm{day}$, out of which, major amount is of biodegradable substances (40-50\%) consisting of organic matter like vegetable peels, and leftover foodstuffs. Combustible fraction accounts for $20-25 \%$ of waste and rest is the inert fraction which includes sand, dust, glass and others. All this waste is produced by residential, commercial, institutional, municipal services, industrial and agricultural uses.

\section{Materials and methods}

This case study was carried out to estimate the waste collection, transport and transfer system to find out problems from those activities and then purpose the solutions by using GIS application. For collection and transport system, surveys were conducted on waste collection vehicles as handcrafts and waste transport vehicles as trucks by using manual GIS application. ArcGIS was used to create maps for MSWM. The original map of Chandigarh was scanned and registered/geo-referenced to specify its location. Thereafter, the collected data for various sanitary wards, collection routes, depots locations, and disposal sites were given as input parameters for the generation of MSWM maps for Chandigarh city using ArcGIS applications. The sanitary wards were drawn and input properties such as name, number, generation rate, and the disposal site (Fig. 2). The location of distribution in each ward, collection sites are determined (Fig. 3). Then, the properties of each disposal site, such as name, capacity and amount of MSW disposed daily (Fig. 4).

\section{Proposed model}

Waste may be defined as useless, unwanted and discarded material which results from a number of activities going on in the locality. It may include left over from kitchen, old newspaper, broken crockery or other home materials, worn out clothes, plastic/glass bottles, tree shedding/leaves, sewage from toilets, ash from hearths, emission from chimneys/vehicles, effluents from industries, and so on. It may be in solid (garbage from homes), liquid (polluted water from industries) or gaseous (smoke from thermal plants) state. Municipal solid waste includes the following elements; waste generation, waste storage, waste collection, transfer and 
transport, waste processing, waste recovery/ recycling, and waste disposal. Solid waste management is of paramount importance in the context of urban areas/cities. In urban India, per capita solid waste of about $0.5 \mathrm{~kg}$ is produced daily, which varies from $0.3 \mathrm{~kg}$ in small towns to around $1 \mathrm{~kg}$ in metro cities. Chandigarh 'the city beautiful' is one of the cleanest cities of India.

Waste collection and storage are interrelated functional elements of MSWM system. Collection of waste includes gathering of wastes and hauling them to the location, where it is collected by emptying the collection vehicle. It may be disposal site, transfer station, or a processing unit. On the other hand, storage is a key functional element because collection of waste never takes place at the source or at the time of its generation. Onsite storage is of primary importance due to aesthetic consideration, public health, as well as economics involved in it. Depending upon the type of waste as well as the frequency of waste generated in the locality, storage size, form and material of storage containers is utilized. The proposed model for Chandigarh Administration will started its MSW plan according to proposed model for save money and manpower.

The proposed model includes different pathway of proper and safe management system. The thickness of the lines represents the amount of waste (kt). Indication points of $(1,8,10)$ is source separation method, $(2,9,11)$ is mixed waste (3) is compostable, (4) is residue, (6) is compostable waste, (7) is compost, (12) is recovered material (13) is residue, (14) is compostable waste, (15) is ash sludge (16) is after remaining $3 \mathrm{R}$ technology waste which is increased the specific land filling costs $(40 \%$ is centrally separated when running the scenario without the landfill limitations) (Fig. 5)

\section{Results and discussion}

The result of the analyze shows that MSW contains $45.3 \%$ organic matter and $40 \%$ miscellaneous materials (bricks, fine dust, rubber, wood, leather, wastewater, etc.). The percentage of recyclable materials (glass, paper, plastic, metals) has been found to be very low. This may be due to rag pickers, who collect and segregate recyclable materials from collection points and disposal sites.

The results from the survey reveal that the per capita MSW generation rate is $0.39 \mathrm{~kg} /$ capita/day. The per capita generation rate for various areas in Chandigarh city. It is also revealed that $88 \pm 3.6 \%$ of people living in houses dispose of their garbage daily, in which $53.4 \pm 4 \%$ are disposing waste in containers, whereas $46.4 \pm 4.2 \%$ are disposing on the streets. Further, $20.4 \pm 6.8 \%$ of houses are segregating their solid waste (biodegradable/ non-biodegradable), 39.5\% are using polyethylene bags for storage and $63.5 \pm 5.9 \%$ of houses are fully aware of government's policy (government bans the using of plastic and polythene bags because they are not easily biodegradable and they create many problems to the environment).

The collection frequency of MSW is shows that $42.7 \pm 5 \%$ of houses are paying for solid waste collection services to local sweepers, and $45.6 \pm 3.5 \%$ are willing to pay for the improvement of solid waste services. About $23 \pm 3.6 \%$ of houses have complained of poor services and others $(39.7 \pm 5.4 \%)$ have been satisfied by the complaint office. The survey also reveals that $34.8 \pm 4.1 \%$ of the people are satisfied with solid waste collection services and their satisfaction 
A. Khajuria, T. Matsui and T. Machimura / Our Nature (2011) 9: 26-33

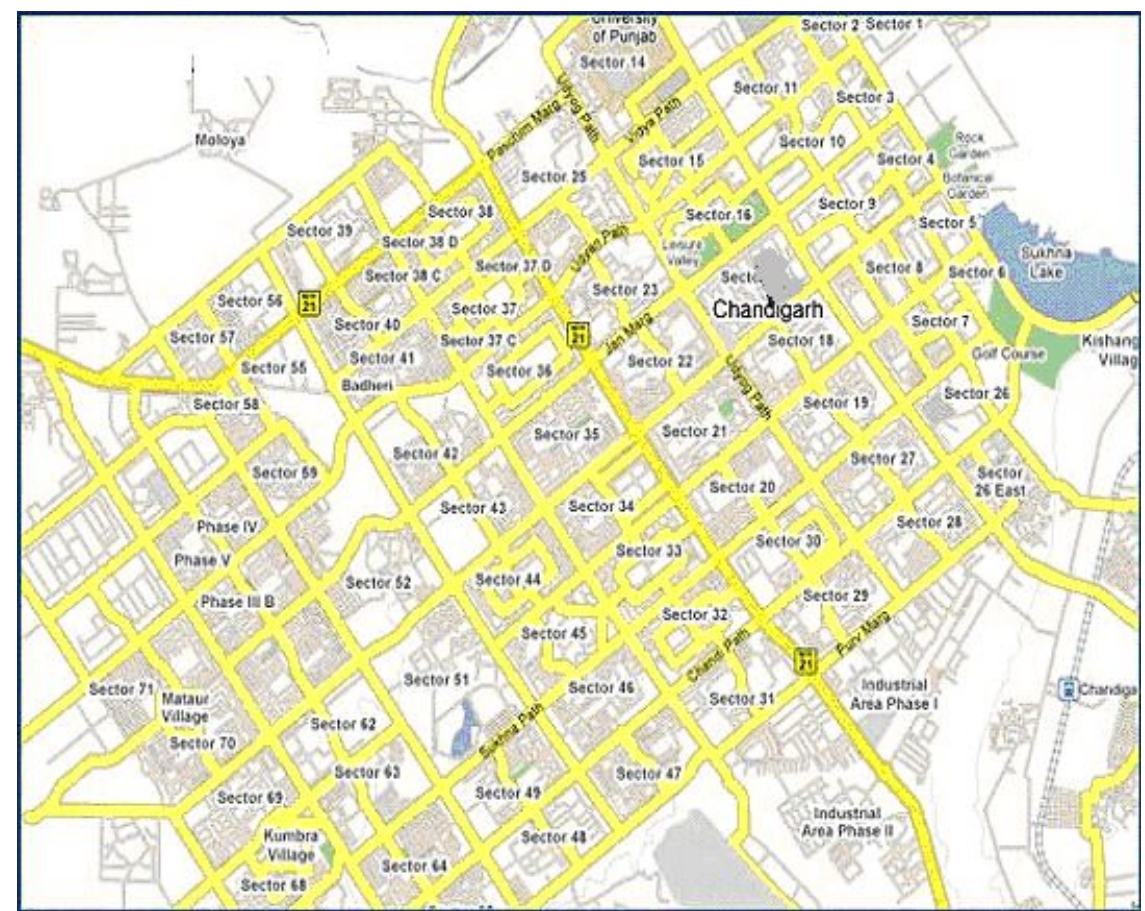

Figure 2. Sanitation zones in Chandigarh ward wise (Kaur et al., 2010).

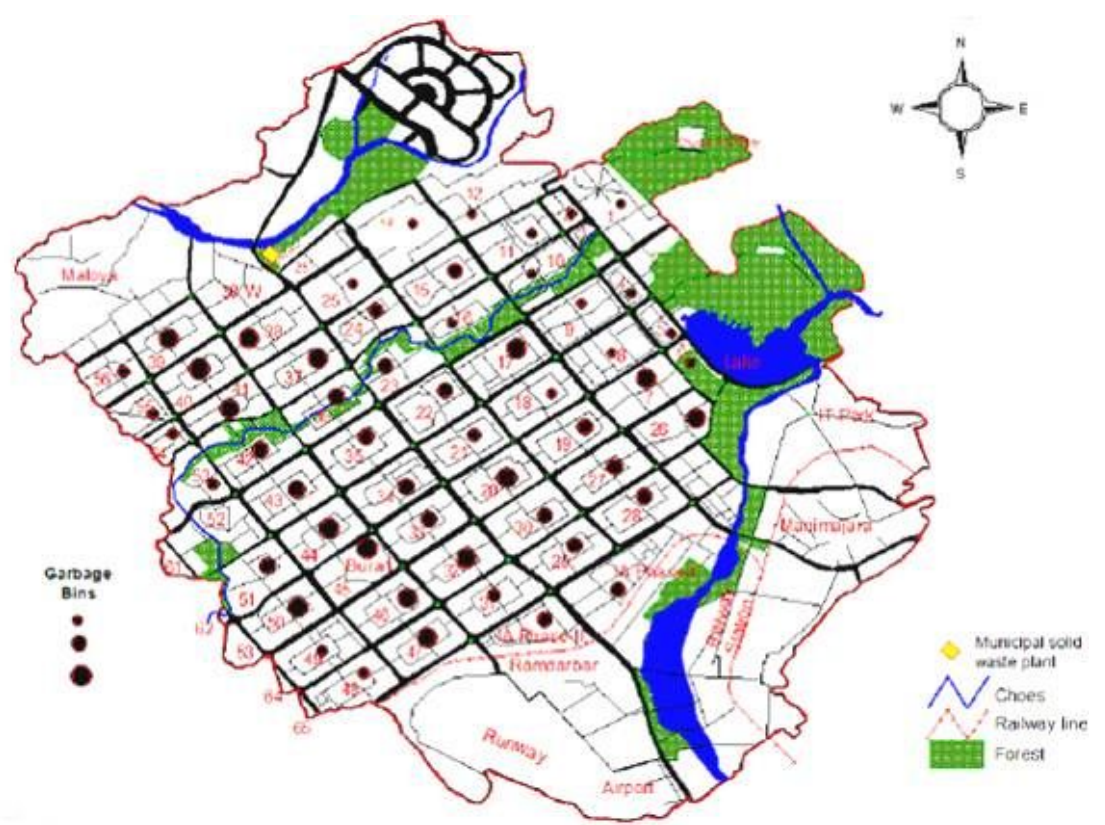

Figure 3. Distribution of location and collection site of MSW in Chandigarh city (Kaur et al., 2010). 
A. Khajuria, T. Matsui and T. Machimura / Our Nature (2011) 9: 26-33

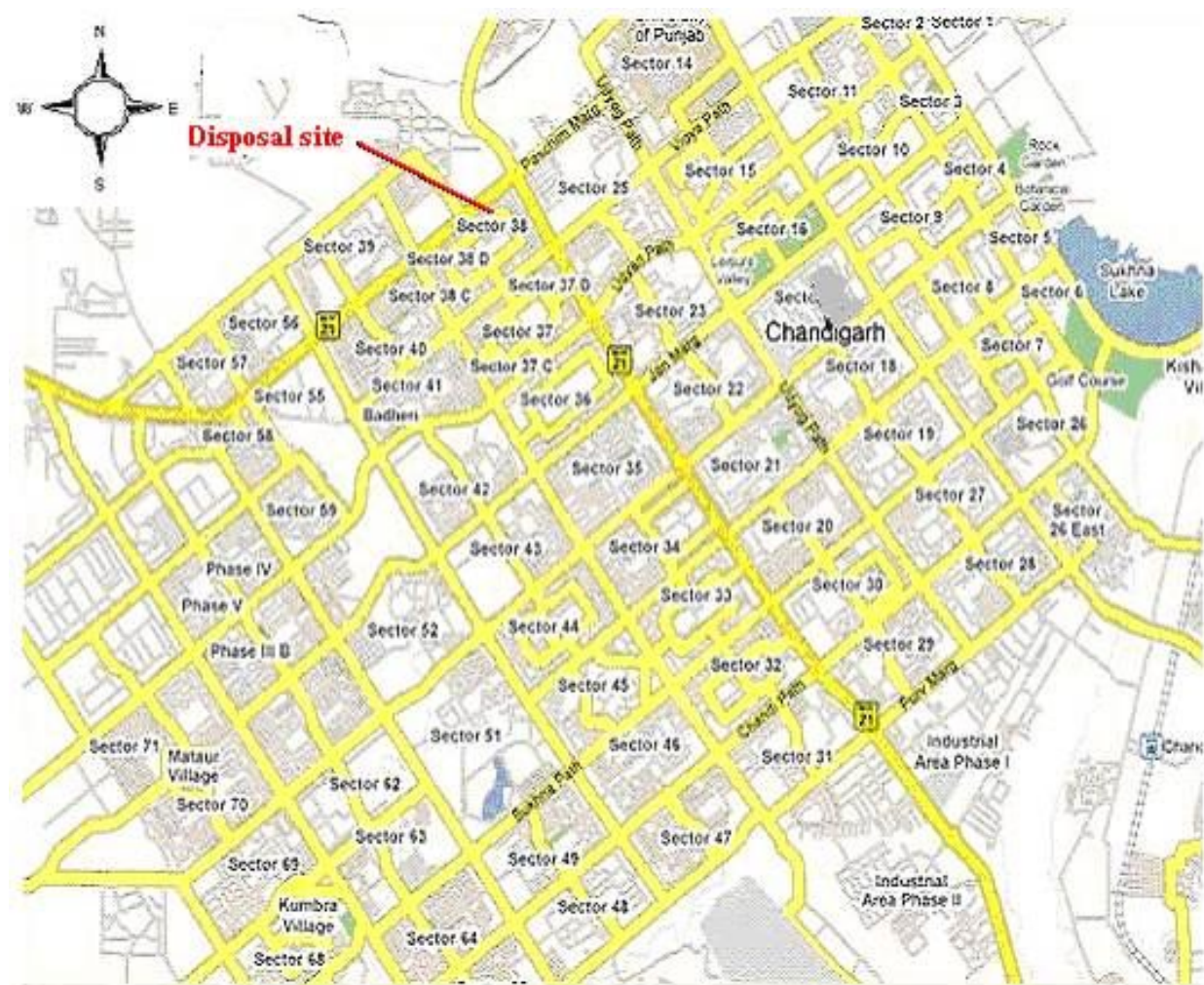

Figure 4. Existing MSW disposal site of Chandigarh city (Ministry of Urban Development, 2001)

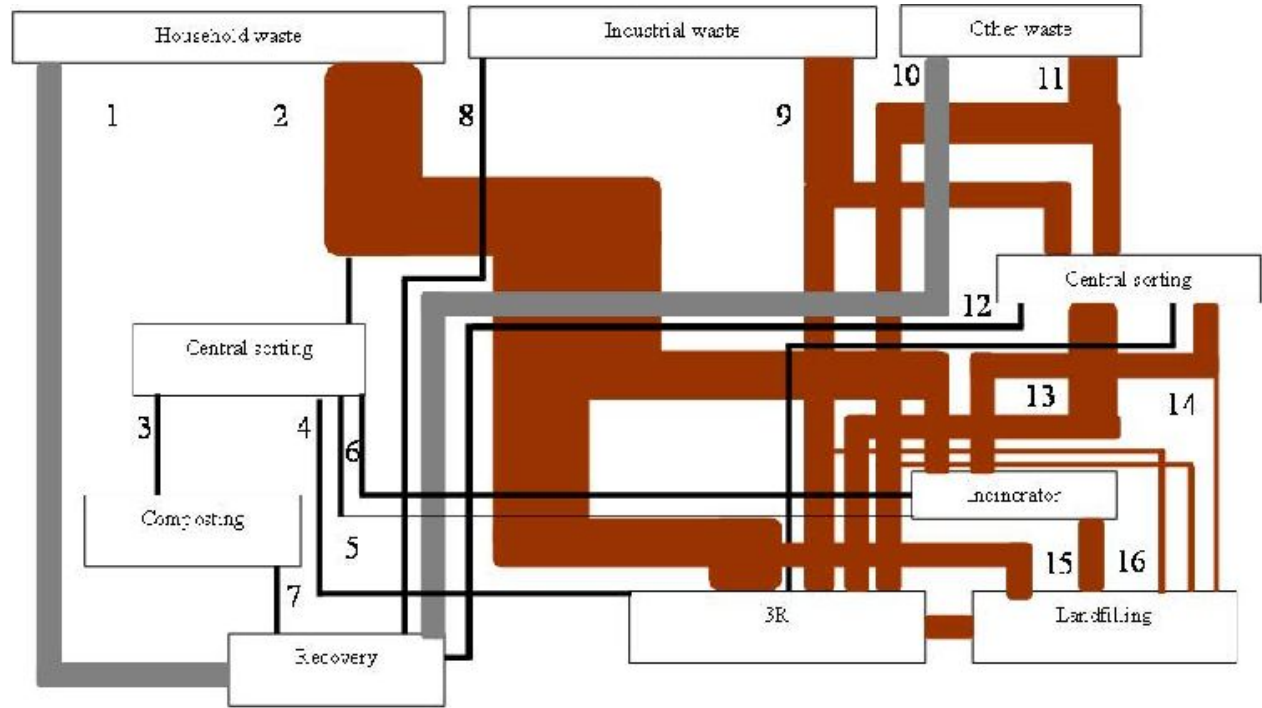

Figure 5. Municipal solid waste management system model. 
levels. Similarly study was done by Kaur et al. (2010).

The results from data analysis in GIS are products of the appropriate format maps concerning static and dynamic parameters of the MSWM problem, such as the productivity of MSW in the different wards, collection point locations, types of MSW transport means and their routes, and the number of disposal sites and their attributes. The locations of these distribution are scattered, unplanned and cover only about $50 \%$ of total area. The information clearly indicates the poor MSW services of Chandigarh city having scant attention in establishment of depots for different prime locations of the city.

The sector 38 disposal site serves the maximum number of wards, whereas other site serves the minimum. This can be balanced by diverting MSW from a few wards towards other sites, but the enhancement of capacity of these sites is required. The MSWM data obtained from ArcGIS maps are responsible for the retrieval, update and visualization of the information required. The produced maps can provide Chandigarh Municipal Corporation, environmental engineers and decision makers with data about the present MSWM system, which is required for improvement of the existing system and for future planning.

\section{Conclusion}

The segregation of waste at source and promotion of recycling or reuse of segregated materials reduces the quantity of waste and the burden on landfills, and provides raw materials for manufacturers. The composition of MSW shows mostly organic matter, so composting is a good method for the treatment and production of soil amendment. The rapid increases in the quantity of MSW but its inability to provide daily collection service cause a nuisance and health hazards. The study presents the current scenario of MSWM, which will be helpful in creating awareness among the people. The MSWM data obtained from ArcGIS maps are responsible for the retrieval, update and visualization of the information required. The produced maps can provide environmental engineers and decision makers with data about the present MSWM system, which is required for the improvement of the existing system and for future planning.

The proposed model customized to Indian Municipal Solid Waste involves the conversion of waste (mainly combustible fraction) into densely packed fluff/pellets with the calorific value, which is free from any harmful by-products and effluents. The practice activity resulting in reduction of methane emission, a potent green house gas by avoiding anaerobic decomposition of untreated MSW in unsecured landfill sites, which was the earlier practice of disposal of MSW in Chandigarh, the 'city beautiful'. In the absence of this green-tech fuel processing plant, dumping of MSW in open/unsecured landfill site in Chandigarh would have continued and there would have not been any reduction in green house gas emissions. Thus it kills two birds with one stone-environment friendly waste disposal and power generation. With the starting of this MSWM processing unit, Chandigarh the city beautiful has also emerged as a green and environment friendly city.

\section{References}

Apaydin, O. and M.T. Gonullu 2008. Emission control with route optimization in solid waste 
A. Khajuria, T. Matsui and T. Machimura / Our Nature (2011) 9: 26-33

collection process: a case study. Sadhana 33: 7782 .

Ghose, M.K., A.K. Dikshit and S.K. Sharma 2006. A GIS based transportation model for solid waste disposal- A case study on Asansol municipality. Waste Management 26: 1287-1293.

Kaur, P., K.D. Singh and Kamalpreet 2010. Municipal solid waste management in developing countries: a case study of Chandigarh. In: Proceedings of Third International Symposium on Energy from Biomass and Waste. Venice, Italy. 8-11 November, 2010 .

Khajuria, A., T. Matsui, T. Machimura and T. Morioka 2010. Assessment of the challenge of sustainable recycling of municipal solid waste management in India. International Journal of
Environmental Technology and Management 13(2): 171-187.

Krishna, G. 1996. Waste management and land use planning. In: Environment education (Ed. H.M. Dhani). Punjab University Press, Chandigarh.

Map of research area. http://gauransh.com/sale/html downloaded on $1^{\text {st }}$ July, 2010.

Ministry of Urban Development 2001. Finance Secretary Chandigarh Administration.

Sharholy, M., K. Ahmad, R.C. Vaishya and R.D. Gupta 2007. Municipal solid waste characteristics and management in Allahabad, India. Waste Management 27: 490496.

Wilson, B.G. and J.K. Vincent 2008. Estimating waste transfer station delays using GPS. Waste Management 28: 1742-1750. 